\title{
O MOVIMENTO DA ECONOMIA SOLIDÁRIA E SUAS DIRETRIZES EDUCATIVAS
}

\author{
A. A. R. OLIVEIRA* e M. M. PAIVA
}

Universidade Federal do Rio Grande do Norte

alyssonandreregis@hotmail.com*

Artigo submetido em junho/2016 e aceito em julho/2016

DOI: $10.15628 /$ holos.2016.4706

\section{RESUMO}

Quais as diretrizes educativas do Movimento de Economia Solidária? Existe um princípio educativo emancipador? A partir dessas indagações objetivamos elaborar uma discussão teórica sobre o princípio educativo que escolhemos para realizar esta reflexão sobre as bases da política pública de educação do movimento de economia solidária. Desta forma, comungamos do entendimento da formação em economia solidária como uma construção social inerente aos processos de trabalho autogestionários, como elemento fundamental para viabilizar as iniciativas econômicas, para a ampliação da cidadania ativa e do processo democrático, como um movimento cultural e ético de transformação das relações sociais e intersubjetivas como base de um novo modelo de desenvolvimento, reconhecendo a centralidade do trabalho na construção do conhecimento técnico e social, articulando o trabalho e a educação na perspectiva da promoção do desenvolvimento sustentável e orientando ações políticas, culturais e pedagógicasautogestionárias e solidárias.

PALAVRAS-CHAVE: Movimento de Economia Solidária,Diretrizes Educativas,Princípio Educativo Emancipador.

\section{THE SOLIDARITY ECONOMY MOVEMENT AND ITS EDUCATIONAL GUIDELINES}

\begin{abstract}
Which are the educational guidelines of the Solidarity Economy Movement? Is there an Emancipatory Educational Principle? From these enquiries we aim to develop a theoretical discussion on the educational principle that we chose to make this reflection on the foundations of public education policy of solidarity economy movement. Thus, we share the understanding of the formation in solidarity economy as a social construction inherent in self-managing work processes, as a key element to enable economic
\end{abstract}

initiatives for the expansion of active citizenship and the democratic process, as a cultural and ethic movement of transforming the social and interpersonal relations based on a new model of development, recognizing the centrality of the work on the construction of the technical and social knowledge, linking the work and the education in the perspective of promoting sustainable development and guiding the political, cultural, selfmanaged and supportive teaching actions.

KEYWORDS: Solidarity Economy Movement, Educational Guidelines, Emancipatory Educational Principle. 


\section{A EMANCIPAÇÃO COMO ESSÊNCIA DO PRINCÍPIO EDUCATIVO}

Neste estudo, realizaremos uma análise sobre as diretrizes educativas que revestem o Movimento de Economia Solidária - MESi a partir de seu entendimento e ação enquanto política pública. Para a realização desta leitura, apropriamo-nos dos principais documentos que regem o fazer pedagógico do movimento para compreender sua proposta enquanto princípioeducativo.

O Movimento de Economia Solidária enquanto fenômeno social e político recente era, e continua sendo, pouco conhecido e reconhecido na sociedade brasileira. Disto resultou o primeiro grande desafio que foi o de realizar um mapeamento nacional dos Empreendimentos Econômicos Solidários - EESii, por parte do Sistema Nacional de Informações em Economia Solidária - SIESiii (2013) e de suas formas de organização. O conhecimento da realidade era fundamental para o seu reconhecimento enquanto prática social inovadora e de seu potencial transformador. Utilizando uma metodologia que procurou conciliar a mobilização participante e as exigências de objetividade, realizou-se um mutirão nacional para identificar a economia solidária em todo o território nacional. Além do mapeamento, a organização de um sistema de informações capaz de contribuir para o fortalecimento da própria ES e melhor orientação para as políticas públicas.

A partir deste mapeamento, também foi possível, neste campo de conhecimento, contribuir com outra agenda, a qual se refere à formação e à educação para oMES. Embora a Economia Solidária seja "um ato pedagógico em si mesma, na medida em que propõe nova prática social e um entendimento novo dessa prática" (SINGER, 2007, p. 55), ela exige possibilidades amplas de reflexão sobre sua prática e socialização dos acúmulos teórico-conceituais que sistematizam dialeticamente tais atos pedagógicos.

Sob essa perspectiva, a estruturação de uma política pública de direito ao conhecimento tem sido uma demanda constante dos Empreendimentos Econômicos Solidários, tendo emergido como prioridade nas Conferências Nacionais e no Conselho Nacional. A Secretaria Nacional de Economia Solidária - SENAES ${ }^{i v}$ e o movimento social realizaram a elaboração de uma proposta de política nacional de formação/educação e assessoramento técnico. Neste caso, os avanços são ainda incipientes, mas já sinalizam os rumos para o futuro desta agenda da ES.

A educação na economia solidária tem motivado muitos de seus participantes a sistematizar suas práticas socioeducativas, na tentativa não apenas de construir novas metodologias, mas também de descobrir seu potencial transformador. De acordo com Oliveira (2012), a pergunta que motiva os que fazem a economia solidária é saber que paradigma filosófico está contido nas metodologias da educação da economia solidária. A autora dá continuidade a esta reflexão quando afirma que "cada vez mais crescem as tendências dos que afirmam ser essa metodologia a expressão de uma filosofia própria [...]" (p. 178). Diante disto, o tema do conhecimento é central para oMES. Desta centralidade, resultou um esforço permanente da SENAES de traduzir, para sua agenda de ação, as experiências e as demandas elaboradas pelo movimento social e seus sujeitos.

Com base nas leituras sobre o movimento da economia solidária, destacamos a Política Pública de Qualificação, que tem se afirmado como um fator de inclusão social e de desenvolvimento econômico, com geração de trabalho e distribuição de renda, norteando-se como uma concepção de qualificação, entendida como uma construção social, de maneira a fazer um contraponto àquelas que se fundamentam na aquisição de conhecimentos como processos estritamente individuais e como uma derivação das exigências dos postos de trabalho. 
O Plano Nacional de Qualificação - PNQ configurou-se numa iniciativa fundamental para se fazer frente às exigências e demandas da ES no que diz respeito à formação social e profissional das pessoas a ele associados. A Resolução 333/2003, do Conselho Deliberativo do Fundo de Amparo ao Trabalhador - CODEFAT, no seu Artigo 8o, já reconhecia, dentre a população prioritária do PNQ, "os/as trabalhadores/as de ações de economia solidária" e "as pessoas que trabalham em condição autônoma, por conta própria, cooperativada, associativa ou autogestionada".

Assim sendo, no âmbito das ações de qualificação do PNQ, abriu-se um canal institucional de interlocução e diálogo para a construção de um projeto apropriado à ES. A primeira iniciativa para estabelecer esta parceria foi a elaboração e a publicação, pela SENAES, em parceria com a Secretaria de Políticas Públicas de Emprego - SPPE, do Termo de Referência em Economia Solidária no Plano Nacional de Qualificação 2003 - 2007, o qual sistematizou as possibilidades de integração das políticas de qualificação social e profissional às políticas de trabalho, renda e desenvolvimento fundamentadas na ES. Outra contribuição oferecida pelo Termo de Referência foi o reconhecimento e a valorização do conjunto de conhecimentos historicamente construídos pelos trabalhadores na organização de iniciativas econômicas fundamentadas na autogestão, na cooperação e na solidariedade. Nas ações de formação social e profissional em ES, tais conteúdos deveriam estar integrados na construção metodológica dos projetos educativos desenvolvidos no âmbito do PNQ.

O Art. 70 do Projeto de Lei $4685 / 2012^{v}$ destaca um conjunto de eixos de ação ligados à Política Nacional de Economia Solidária, interessando-nos destacar um desses eixos, acerca da educação, da formação, da assistência técnica e da qualificação social e profissional no meio rural e urbano. Em complementaridade, o Art. 9o afirma que a implementação das ações de educação, formação, assistência técnica e qualificação previstas nesta Política Nacional de Economia Solidária incluirá a elevação de escolaridade, a formação para a cidadania e para a prática da autogestão e a qualificação técnica e tecnológica para a formação de Empreendimentos Econômicos Solidários.

Ainda dentro deste contexto, destacamos:

$\S 1$ 을 As ações educativas e de qualificação em economia solidária, visando à formação sistemática de trabalhadores dos Empreendimentos Econômicos Solidários, bem como de formadores e gestores públicos que atuam na economia solidária, serão realizadas prioritariamente de forma descentralizada, por instituições de ensino superior, de entidades da sociedade civil sem fins lucrativos e de governos estaduais e municipais.

§ 2ㅇ A Política Nacional de Economia Solidária buscará implantar núcleos e redes, de caráter local, regional e nacional, de assistência técnica, gerencial, de assessoria e acompanhamento aos Empreendimentos Econômicos Solidários, utilizando-se de metodologias adequadas a essa realidade, valorizando as pedagogias populares e participativas e os conteúdos apropriados à organização na perspectiva da autogestão, tendo como princípio a autonomia a partir dos princípios e metodologia da educação popular.

A formação emerge como uma das principais demandas da economia solidária no Brasil. Ela foi incluída como eixo do movimento que orienta as ações e lutas do Fórum Brasileiro de Economia Solidária - FBESvi. As ações de qualificação para a economia solidária devem fortalecer o seu potencial de inclusão social e de sustentabilidade econômica, bem como sua dimensão emancipatória. Outro componente estratégico da plataforma do FBES é a promoção da educação de 
novas gerações por meio da incorporação de programas sobre a Economia Solidária junto ao Ministério da Educação e Cultura - MEC, da pré-escola, passando pelo ensino fundamental, médio, superior e pós-graduação, introduzindo valores da cultura solidária e pedagogias que favoreçam a solidariedade e a construção de um novo modelo de sociedade.

A SENAES tem clareza da importância da educação para o fortalecimento da economia solidária. Além da promoção e da divulgação da ES no Brasil, o Departamento de Estudos e Divulgação - DED também tem atribuições relativas à formação. O Decreto 5.063, de 03 de maio de 2004, que trata da estrutura regimental do Ministério do Trabalho e Emprego, estabelece, no Artigo 19, item II, que uma das competências do DED é "Articular-se com o Departamento de Qualificação, da Secretaria de Políticas Públicas de Emprego, para a promoção de ações de formação no campo da economia solidária".

Podemos seguramente afirmar que a educação para a economia solidária é um grande desafio, em especial, para os Empreendimentos Econômicos Solidários. Seu intenso crescimento nos últimos anos exige respostas adequadas e permanentes às suas necessidades de formação e assistência técnica. Os trabalhadores da economia solidária deparam-se no cotidiano com exigências cada vez mais complexas relativas aos processos de autogestão de suas iniciativas coletivas, bem como da necessária busca da eficiência e viabilização das atividades econômicas que realizam. Para isso, faz-se fundamental combinar processos educativos integrados com as oportunidades de elevação de escolaridade e outras iniciativas que contribuam para a formação política cidadã. Igualmente, é necessário que a educação contribua para o fortalecimento da economia solidária enquanto uma prática social transformadora e emancipatória.

A Economia Solidária exige uma educação que transforme a mentalidade cultural dominante de competição para a construção do espírito de cooperação, além do desenvolvimento de uma matriz científica e tecnológica comprometida com o desenvolvimento sustentável e solidário. A partir de nossas leituras, percebemos o registro no Termo de Referência em Economia Solidária no Plano Nacional de Qualificação 2003 - 2007 de que a Educação para a Economia Solidária, seguindo os princípios da solidariedade e autogestão, contribui para o desenvolvimento de um país mais justo e solidário. Ela deverá valorizar as pedagogias populares e suas metodologias participativas e os conteúdos apropriados à organização, na perspectiva da autogestão, tendo como princípio a autonomia, devendo viabilizar tecnicamente as suas atividades sociais e econômicas e despertar a consciência crítica dos trabalhadores. A complexidade desta formação inclui tanto estes princípios, enquanto ferramentas para o empoderamento dos sujeitos, como a capacitação técnica, a inclusão digital e a própria prática da autogestão.

Com base no Plano Nacional de Qualificação (2003), percebemos que o nexo entre trabalho, educação e desenvolvimento, no âmbito das Políticas Públicas de Qualificação, pressupõe a promoção de atividades político-pedagógicas baseadas em metodologias inovadoras dentro de um pensamento emancipatório de inclusão, tendo o trabalho como princípio educativo, o direito ao trabalho como um valor estruturante da cidadania, a qualificação como uma política de inclusão social e um suporte indispensável do desenvolvimento sustentável e a associação entre a participação social e a pesquisa como elementos articulados na construção desta política e na melhoria da base de informação sobre a relação trabalho-educação-desenvolvimento, possibilitando, assim, a melhoria das condições de trabalho e da qualidade social de vida da população. 
Com este entendimento de educação no movimento de economia solidária, um tema/conteúdo significativo em sua essência é o caráter emancipatório e a superação do trabalho alienado. Os debates conduzem a um consenso sobre um princípio básico: (a) a política pública nacional de formação em ES deverá ser articulada ao processo permanente de fortalecimento e emancipação; (b) existência do movimento de ES (articulação e estruturação dos fóruns e demais mecanismos de mobilização); (c) política da ES com sua incorporação na agenda política do país e implementação de programas de apoio massivo, bem como reconhecimento legal que valorize suas especificidades.

Neste estudo, para a discussão da emancipação e seus elementos norteadores, destacaremos alguns grandes intelectuais que têm a educação como objeto de suas preocupações filosóficas. Assim, apropriar-nos-emos, principalmente, das ideias do italiano Antônio Gramsci e do brasileiro Paulo Freire. Mesmo em realidades e contextos distintos, esses autores marcaram a pedagogia, contribuindo com as nossas reflexões sobre o processo educativo nos Empreendimentos Econômicos Solidários.

Ao longo desta discursão, mesmo que de forma intrínseca, temos destacado a importância dos processos de cidadania, autonomia e emancipação sociocultural dos indivíduos que participam de associações, movimentos, projetos sociais, entre outro, envolvendo a produção de saberes e aprendizagens em espaços não escolares, como os Empreendimentos Econômicos Solidários, por exemplo. Por isso, cremos ser necessário precisar melhor a concepção de emancipação social ora tratada e dos possíveis elementos construtores desse conceito.

Ao longo da história da educação, diversos autores têm abordado a temática da emancipação enquanto princípio educativo num debate teórico-reflexivo. É claro que não seria possível falarmos de emancipação e hegemonia sem nos pautarmos nos termos educação e escola, objetos de intensa preocupação de Gramsci, já que ele considera os dois elementos supracitados como se consistissem em um aparelho privado de hegemonia. Assim, apontamos, neste trabalho, algumas ideias, adensando a perspectiva da formação humana para a emancipação, considerando outros espaços não escolares como celeiros de desenvolvimento ideológico contra-hegemônico.

Segundo Gramsci (1982), todo grupo social, ao mesmo tempo em que se constitui sobre a base original da função que assume no campo da produção econômica, cria organicamente uma ou mais camadas de intelectuais que lhe asseguram homogeneidade e consciência de sua própria função, não só no setor econômico, como também nos setores social, político e cultural. Essas camadas intelectuais não surgem de forma abstrata, democrática, liberal, etc., mas sim de relações concretas dentro do processo histórico de produção social, não havendo espaço para que o camponês se emancipasse enquanto produtor de um pensamento autônomo, pois a estrutura, a estratificação social não the permitia alcançar qualquer posto para além da sua condição de trabalhador do campo. Entende-se, assim, que a principal função de formar o sujeito numa perspectiva socialista baseia-se na construção de um indivíduo emancipado e crítico, voltado para a construção de um sujeito que tenha, na sua base intelectual e objetiva da vida social, as "armas" para a construção do ser completo. Em suma, esta concepção de educação tem como princípio a formação do sujeito coletivo, solidário, mais humano, fugindo-se totalmente à concepção capitalista de escola (MONASTA, 2010).

Com base nos estudos de Gramsci, é possível afirmarmos que a educação deveria promover a aprendizagem de conhecimentos emancipatórios, que contribuam para possibilitar o indivíduo de agir conscientemente, engajando-se na luta por transformações das condições perversas, injustas e 
negadoras da dignidade humana. Para isso, é necessário construir outra hegemonia diametralmente contrária à que está posta. Neste aspecto, acreditamos que o pensamento de Gramsci é pedagógico. Acima de tudo, com claro objetivo pedagógico. Instrumentalizar a classe operária, para que ela assuma a consciência da própria história e seja protagonista da sua emancipação (PFAIFER, FRIEDMANN ANGELI, 2010).

A crítica à distinção tradicional entre o "trabalho manual" e o "trabalho intelectual" é um dos elementos mais importantes para a elaboração de uma nova teoria da educação. Segundo Monasta (2010), para Gramsci, essa distinção é ideológica, na medida em que desvia a atenção das funções reais, no interior da vida social e produtiva, para os "aspectos técnicos" do trabalho. Em qualquer trabalho físico, até mesmo no mais degradante e mecânico, existe um mínimo de atividade intelectual. Assim, portanto, podemos dizer que todos os homens são intelectuais: porém nem todos exercem a função de intelectuais na sociedade. Não existe atividade humana da qual se possa excluir absolutamente alguma participação intelectual: não é possível separar o homo faber do homo sapiens.

Para Adorno (1995a), a exigência de emancipação parece ser evidente numa democracia. Para precisar a questão, ele nos remete ao início do breve ensaio de Kant, intitulado "Resposta à pergunta: o que é esclarecimento?". Ali ele define a menoridade ou tutela e, deste modo, também a emancipação, afirmando que este estado de menoridade é autoinculpável quando sua causa não é a falta de entendimento, mas a falta de decisão e de coragem de servir-se do entendimento sem a orientação de outrem. "Esclarecimento é a saída dos homens de sua autoinculpável menoridade" (ADORNO, 1995b, p.177). Esse programa de Kant para Adorno (1995b) é extraordinariamente atual. Adorno, ainda na sua rica teorização, ao falar de emancipação, refere-se à função do esclarecimento, mas, de maneira nenhuma, à conversão de todos os homens em seres inofensivos e passivos. Ao contrário: esta passividade inofensiva constitui ela própria, provavelmente, apenas uma forma da barbárie, na medida em que está pronta para contemplar o horror e se omitir no momento decisivo.

Tomando como base o pensamento do autor, podemos afirmar que, de certo modo, emancipação significa o mesmo que conscientização, racionalidade. Para ele, o conceito de racionalidade ou de consciência é apreendido de um modo excessivamente estreito, como capacidade de pensar. A racionalidade como atitude pessoal consiste na disposição de examinar nossas ideias e opiniões, revisá-las, autocriticá-las e corrigi-las. Isso tudo envolve um fazer, uma prática que se transforma em práxis. A este respeito, Adorno (1995, p. 160) diz:

[...] a consciência é o pensar em relação à realidade, ao conteúdo - a relação entre formas e estruturas de pensamento do sujeito e aquilo que este não é. Este sentido mais profundo de consciência ou faculdade de pensar não é apenas o desenvolvimento lógico formal, mas ele corresponde literalmente à capacidade de fazer experiências.

A análise do processo de emancipação social, política, econômica e cultural remete-nos a refletir sobre vários temas da sociedade, a saber: direitos (civis, culturais e políticos), poder, dominação, etc. Inúmeros processos sociopolíticos emergem nesta análise, tais como: participação, democracia (representativa e participativa), cultura (em suas inúmeras manifestações, principalmente política), cidadania (individual e coletiva), liberdade, resistência, humanização, conscientização, etc. Todos esses processos têm se transformado em categorias analíticas dos pesquisadores que se ocupam em refletir sobre o ser humano e sua trajetória, da busca de lutas por libertação de toda violência, da busca da paz e da felicidade. A análise da emancipação remete-nos 
ao campo dos problemas sociais, dos conflitos, lutas, violência, assim como ao campo dos sonhos, dos desejos, de uma outra sociedade possível. Por esta razão, optamos em nos apoiar nesta análise ao retratarmos o objeto de estudo ora tratado.

Podemos analisar a emancipação tanto como processo individual, focalizando os indivíduos propriamente ditos, ou como processo social, como um conjunto de práticas, ideias e relações que abrangem a sociedade. Para os objetivos deste trabalho, interessa-nos este último tipo, a emancipação social, coletiva, sociopolítica e cultural de grupos, camadas e conjuntos de indivíduos da sociedade a partir do processo educativo que o movimento da economia solidária e os EES favorecem enquanto espaços não escolares a partir de uma educação não formal. Um é parte do outro, mas a somatória dos indivíduos não é o mesmo que o coletivo.

Freire (1985) afirma que a educação sozinha não emancipa ninguém, mas, sem ela, não há emancipação, a qual deve ter por meta sujeitos autodeterminados, livres objetivamente de qualquer tipo de constrangimento ou mazelas que aprisionam os indivíduos. Deve haver emancipação das consciências, para que se compreenda que a realidade em que estamos inseridos não é estática, nem fruto de uma ordem natural ou de qualquer outra força imaterial. É preciso saber refletir sobre essa realidade, percebendo-se como sujeitos históricos que podem se posicionar, emitir opiniões, fazer escolhas, construir rumos para suas vidas.

Jacques Rancière (2007, p. 11-12) é outro filósofo que se ocupa do tema da emancipação. Ele diz:

Não há ignorante que não saiba uma infinidade de coisas, e é sobre este saber, sobre esta capacidade em ato que todo ensino deve se fundar. Instruir pode, portanto, significar duas coisas absolutamente opostas: confirmar uma incapacidade pelo próprio ato que pretende reduzi-la, ou inversamente, forçar uma capacidade que se ignora ou se denega a reconhecer e a desenvolver todas as consequências desse reconhecimento. $O$ primeiro ato chama-se embrutecimento. E o segundo, emancipação.

A emancipação depende dos níveis de consciência do indivíduo, da sensibilidade aos problemas, da capacidade de construir utopias reais e da dimensão do sentido interior que mobiliza e impulsiona as pessoas. De acordo com Freire (1979), em sua obra Educação e Mudança, quando uma sociedade fechada sofre pressão de determinados fatores externos, espedaça-se, mas não se abre. Uma sociedade abre-se quando começa o processo de desalienação com o surgimento de novos valores. O destino do homem deve ser criar e transformar o mundo, sendo o sujeito de sua ação.

\section{ELEMENTOS INTRÍNSECOS AO PROCESSO EDUCATIVO DE EMANCIPAÇÃO}

Nos debates teóricos, foi possível observarmos de maneira latente, como um dos fatores contributivos no princípio educativo de caráter emancipatório, o elemento da autonomia. Comungamos do pensamento de que um movimento de emancipação só pode partir da autoatividade das massas, de sua autonomia, da cisão com a classe dominante. Marcos Del Roio (2007) afirma que Gramsci destaca a representação da vontade coletiva autônoma que se autoorganiza em oposição à ordem social vigente, gerando uma cisão que contesta a subalternidade. Essa demanda, todavia, é uma reforma moral e intelectual, uma transformação cultural de grande envergadura histórica, que supere e substitua a cultura da velha classe dominante. 
Para Castoriadis (1992), uma política de autonomia deve ter como objeto final ajudar a coletividade a criar suas instituições, sem, porém, limitar a capacidade dos indivíduos de serem autônomos. Tomando como base este pensamento, consideramos que a autonomia é requisito básico para a participação política do indivíduo em uma sociedade dita excludente. Somente um indivíduo autônomo é capaz de processar e selecionar informações, ter domínio de conhecimento, tomar decisões e posicionar-se frente a incertezas e conflitos globais. A autonomia leva-o à participação política, não devendo, porém, estar atrelada às justificações de ordem econômica ou ideológica, incapacitando-o ou impedindo-o de ser, de agir nem de entender as contradições que permeiam o mundo globalizado.

Outro elemento presente que conseguimos identificar, sobre o processo educativo de emancipação, a partir da construção deste referencial teórico-metodológico, foi a importância da formação da consciência crítica. Tomando como base inicial de discurso sobre este elemento, apoiamo-nos em uma reflexão que Freire (1967) nos traz em sua obra intitulada "Educação como prática da liberdade". Para ele, a consciência crítica é:

[...] a representação das coisas e dos fatos como se dão na existência empírica. Nas suas correlações causais e circunstanciais. A consciência ingênua (pelo contrário) se crê superior aos fatos, dominando-os de fora e, por isso, se julga livre para entendê-los conforme melhor Ihe agradar. A consciência mágica, por outro lado, não chega a acreditar-se 'superior aos fatos', dominando-os de fora, nem 'se julga livre para entendê-los como melhor Ihe agradar'. Simplesmente os capta, emprestando-lhes um poder superior, que a domina de fora e a que tem, por isso mesmo, de submeter-se com docilidade. É próprio desta consciência o fatalismo, que leva ao cruzamento dos braços, à impossibilidade de fazer algo diante do poder dos fatos, sob os quais fica vencido o homem.

Para a maioria das populações que viveram submetidas a um regime de exclusão social, as condições de trabalho e de vida e o conformismo educacional de suas sociedades não lhes deixaram margem alguma para o pensamento crítico e o desenvolvimento pessoal. Por isso, nós acreditamos que as mensagens de autores como Gramsci, Adorno e Freire, à medida que se esclarecem e emergem das sombras dessa época histórica, ajudam-nos a descobrir um novo enfoque da educação: um enfoque cientificamente crítico de todos os processos ideológicos e educativos. Por isso, desde já, salientamos a necessidade de uma permanente atitude crítica, um meio pelo qual o homem realizará sua vocação natural de integrar-se, superando a atitude do simples ajustamento ou acomodação, apreendendo temas e tarefas de sua época.

De acordo com Freire (1979), a consciência crítica possui um conjunto de características pertinentes para as questões ora tratadas, e destacá-las-emos sinteticamente: (a) anseio de profundidade na análise de problemas. Não se satisfaz com as aparências. Pode-se reconhecer desprovida de meios para a análise do problema; (b) reconhecimento de que a realidade é mutável; (c) substituiçãode situações ou explicações mágicas por princípios autênticos de causalidade; (d) verificação ou testes das descobertas, com constante disposição para as revisões; (e) tentativas, o quanto for possível, para livrar-se de preconceitos, não somente na captação, mas também na análise e na resposta; (f) recusa a posições quietistas, sendo intensamente inquieta. Torna-se mais crítica quanto mais reconhece em sua quietude a inquietude, e vice-versa. Sabe que é na medida que é e não pelo que parece. O essencial para parecer algo é ser algo, é a base da autenticidade; (g) recusa a toda transferência de responsabilidade e de autoridade e aceitaçãoda delegação das 
mesmas; (h) indagação, investigação, força; (i) amor ao diálogo, nutrindo-se dele; (j) face ao novo, não há recusa ao velho por ser velho, nem aceitaçãoao novo por ser novo, mas aceitação a ambos, na medida em que são válidos.

A partir dos pontos ilustrados pelo autor, percebemos a importância do homem consciente e, na medida em que conhece, tende a se comprometer com a própria realidade - tarefa que lhes exige, durante sua ação sobre a realidade, um aprofundamento da sua tomada de consciência da realidade, objetode atos contraditórios daqueles que pretendem mantê-la como está e dos que pretendem transformá-la. A conscientização, que lhe possibilita inserir-se no processo histórico, como sujeito, evita os fanatismos e o inscreve na busca de sua afirmação. "Se a tomada de consciência abre o caminho à expressão das insatisfações sociais, se deve a que estas são componentes reais de uma situação de opressão" (FREIRE, 1967, p. 11).

Segundo Gramsci (1982), a libertação do homem toma a forma da compreensão do grupo social que tem uma própria concepção de mundo. Esta concepção articula-se organicamente para construir uma hegemonia dominante sobre as classes subalternas. Por isso, é necessário um esforço e disciplina intelectual por parte dos indivíduos, para que possam exprimir uma concepção de classe. Entendemos que esta consciência crítica deve estar a serviço da organização e da unidade da classe subalterna, visto que, histórica e politicamente, ela não as possui.

A questão fundamental, neste caso, segundo Freire (1967), está em que, faltando aos homens uma compreensão crítica da totalidade em que estão, captando-a em pedaços nos quais não reconhecem a interação constituinte da mesma totalidade, não podem conhecê-la. E não o podem porque, para conhecê-la, seria necessário partir do ponto inverso. Isto é, ser-lhes-ia indispensável ter, antes, a visão totalizada do contexto para, em seguida, separarem ou isolarem os elementos ou as parcialidades do contexto, através de cuja cisão voltariam com mais claridade à totalidade analisada. Esta ideia esboçada pelo autor nos sugere um esforço que cabe realizar na educação para a emancipação que adotamos como perspectiva reflexiva neste estudo. O esforço de propor aos indivíduos dimensões significativas de sua realidade, cuja análise crítica lhes possibilite reconhecer a interação de suas partes, seria um ponto importante no processo educativo para a autonomia e a liberdade. Salientamos, ainda, que esta conscientização, é óbvio, não para no reconhecimento puro (de caráter subjetivo) da situação, mas, pelo contrário, prepara os homens (no plano da ação) para a luta contra os obstáculos à sua humanização. Mediante perspectiva apontada sobre o tema consciência crítica, entendemos que o ato pedagógico deve estar aberto à contínua reflexão crítica, para possibilitar um espaço de permanente reflexão sobre as práticas e um aprofundamento sobre a ES, suas relações com a realidade social existente e seu potencial transformador desta realidade.

Um elemento ainda presente neste discurso teórico sobre princípio educativo emancipatório e que anda lado a lado da conscientização refere-se à temática da liberdade. Liberdade deve ser outra categoria também lembrada quando falamos de educação não formal, dada a força motivadora de suas práticas, geradoras de processo incentivador na busca e produção de saberes que podem vir a ser ferramentas importantes para os indivíduos aprenderem a fazer leituras próprias do mundo em que vivem, dos fatos sociais que os circundam.

Freire (1967) destaca,em sua consagrada obra Pedagogia do Oprimido, um aspectoque o surpreende, quer nos cursos de capacitação à frente dos quais ele esteve, e em que analisa o papel da conscientização, quer na aplicação mesma de uma educação realmente libertadora: é o "medo da liberdade". O "medo da liberdade", de que se fazem objeto os oprimidos, medo da liberdade que 
tanto pode conduzi-los a pretender ser opressores também, quanto pode mantê-los atados ao status de oprimidos, é outro aspecto que merece igualmente nossa reflexão. Um dos elementos básicos na mediação opressores-oprimidos é a prescrição. Toda prescrição é a imposição da opção de uma consciência a outra. Daí o sentido alienador das prescrições que transformam a consciência recebedora no que vimos chamando de consciência "hospedeira" da consciência opressora. Por isso, o comportamento dos oprimidos, na visão do autor, é um comportamento prescrito. Faz-se à base de pautas estranhas a eles - as pautas dos opressores.

Este medo da liberdade, tão salientado pelo autor, também se instala nos opressores, mas, obviamente, de maneira diferente. Nos oprimidos, o medo da liberdade é o medo de assumi-la. Nos opressores, é o medo de perder a "liberdade" de oprimir. Assim é que, enquanto a prática bancária, como enfatizamos, implica uma espécie de anestesia, inibindo o poder criador dos educandos, a educação problematizadora, de caráter autenticamente reflexivo, implica um constante ato de desvelamento da realidade. A primeira, segundo o autor, pretende manter a imersão; a segunda, pelo contrário, busca a emersão das consciências, de que resulte sua inserção crítica na realidade. Se esta educação só é possível enquanto compromete o educando como homem concreto, ao mesmo tempo o prepara para a crítica das alternativas apresentadas pelas elites e dá-lhe a possibilidade de escolher seu próprio caminho.

O historicismo, ao contrário, integra liberdade com necessidade e se acautela diante da expressão marxista "passagem do reino da necessidade para o reino da liberdade". (GERRATANA, 1975). A compreensão dessa pedagogia em sua dimensão prática, política ou social, requer, portanto, clareza quanto a este aspecto fundamental: a ideia da liberdade só adquire plena significação quando comunga com a luta concreta dos homens por libertar-se.

Ainda segundo Freire (1985), a ação política junto aos oprimidos tem de ser, no fundo, "ação cultural" para a liberdade, por isso mesmo, ação com eles. A sua dependência emocional, fruto da situação concreta de dominação em que se acham e que gera também a sua visão inautêntica do mundo, não pode ser aproveitada a não ser pelo opressor. Este é que se serve desta dependência para criar mais dependência. A ação libertadora, pelo contrário, reconhecendo esta dependência dos oprimidos como ponto vulnerável, deve tentar, por meio da reflexão e da ação, transformá-la em independência. Esta, porém, não é doação que uma liderançalhes faça, por mais bemintencionada que seja. Não podemos esquecer que a libertação dos oprimidos é libertação de homens, e não de "coisas". Por isso, se não é autolibertação (ninguém se liberta sozinho), também não é libertação de uns feita por outros. Libertar-se de sua força exige, indiscutivelmente, a emersão dela, a volta sobre ela. Por isso é que, segundo o autor, só por meio da práxis autêntica, ou seja, ação e reflexão, é possível fazê-lo.

Valemo-nos aqui de alguns questionamentos trazidos na obra Pedagogia do Oprimido: quem, melhor que os oprimidos, se encontrará preparado para entender o significado terrível de uma sociedade opressora? Quem sentirá, melhor que eles, os efeitos da opressão? Quem, mais que eles, para ir compreendendo a necessidade da libertação?

Este é o trágico dilema dos oprimidos, configurado por Freire e que a sua pedagogia tem de enfrentar. A libertação, por isso, é um parto. E um parto doloroso. O homem que nasce desse parto é um homem novo que só é viável na e pela superação da contradição opressores-oprimidos, que é a libertação de todos. Libertação a que não chegarão pelo acaso, mas pela práxis de sua busca, pelo conhecimento e reconhecimento da necessidade de lutar por ela. Luta que, pela finalidade que lhe 
derem os oprimidos, será um ato de amor, com o qual se oporão ao desamor contido na violência dos opressores, até mesmo quando esta se revista da falsa generosidade referida.

\section{ALGUMAS REFLEXÕES FINAIS}

A reflexão teórico-metodológica trazida neste estudo indica a importância da dimensão formativa para a política pública de Economia Solidária. Percebe-se que a formação não é apenas uma atividade transversal aos projetos desenvolvidos, mas constitui-se na própria base de sustentação dessas iniciativas. Esta discussão leva-nos a crer que a educação para a Economia Solidária, seguindo os princípios da solidariedade e autogestão, contribui para o desenvolvimento de um país mais justo e solidário. Ela deverá valorizar as pedagogias populares e suas metodologias participativas e os conteúdos apropriados à organização, na perspectiva da autogestão, tendo como princípio a autonomia. Deve viabilizar tecnicamente as suas atividades sociais e econômicas e despertar a consciência crítica dos trabalhadores.

Desta forma, comungamos do entendimento da formação em economia solidária como uma construção social inerente aos processos de trabalho autogestionários, como elemento fundamental para viabilizar as iniciativas econômicas, para a ampliação da cidadania ativa e do processo democrático, como um movimento cultural e ético de transformação das relações sociais e intersubjetivas como base de um novo modelo de desenvolvimento, reconhecendo a centralidade do trabalho na construção do conhecimento técnico e social, articulando o trabalho e a educação na perspectiva da promoção do desenvolvimento sustentável e orientando ações político, culturais e pedagógicas autogestionárias e solidárias.

A partir desta breve discussão sobre Educação e Economia Solidária, bem como de um olhar com base na educação não formal, pretendemos realizar uma análise reflexo-contributiva deste cenário educativo, percebendo, ainda, que o crescimento do MES no contexto brasileiro deve-se a fatores variados, dentre os quais, vale destacar a resistência de trabalhadores à crescente exclusão social, desemprego urbano e desocupação rural, resultantes da expansão agressiva dos efeitos negativos da globalização da produção capitalista. Tal resistência manifesta-se, primeiramente, como luta pela sobrevivência, na conformação de um mercado informal crescente, onde brotam iniciativas de economia popular, tais como a atuação de camelôs, flanelinhas, vendedores ambulantes, entre outros, normalmente de caráter individual ou familiar. Com a articulação de diversos atores, essa resistência também se manifesta na forma de iniciativas associativas e solidárias, voltadas também à reprodução da vida, mas que vão além disso, apontando para alternativas estruturais de organização da economia, baseada em valores como a ética, a equidade e a solidariedade, e não apenas no lucro e acúmulo indiscriminado.

Tomando como base o cenário aqui apresentado, acreditamos que uma das bandeiras de luta do Movimento de Economia Solidária respalda-se no elemento formação, fator primordial para a atuação dos EES frente ao contexto de construção e fortalecimento discutidos nas seções anteriores. Assim, percebemos que seria oportuno o levantamento de mais algumas questões que serão em futuros: como se configura a ação educativa desenvolvida junto aos EES? As ações educativas têm levado a um contexto de emancipação humana?Quais o sentido e significado das ações educativas para os sujeitos participantes dos EES? 


\section{REFERÊNCIAS BIBLIOGRÁFICAS}

1. ADORNO, T. W. A educação contra a barbárie. In: ADORNO, T. W. Educação e Emancipação. Rio de Janeiro: Paz e Terra, 1995a, p. 155-168.

2. _. Educação e Emancipação. In: ADORNO, T. W. Educação e Emancipação. Rio de Janeiro: Paz e Terra, 1995b, p. 169-185.

3. BRASIL. Conteúdos básicos na trajetória da formação Técnica Geral. Formação Técnica Geral: Livro do Educador. Brasília: Ministério do Trabalho e Emprego, 2011. Disponível em: <http://portal.mte.gov.br/data/files/8A7C816A3D183F81013D3AC35F881290/PNQ\%20conte udos\%20gerais\%20-\%20Livro\%20do\%20ALUNO.PDF>. Acesso em: 01 Mar. 2015.

4.

Decreto-lei n.o 5.063, de 03 de maio de 2004. Aprova a Estrutura Regimental e o Quadro Demonstrativo dos Cargos em Comissão e das Funções Gratificadas do Ministério do Trabalho e Emprego, e dá outras providências. Diário Oficial da União, Brasília (DF): 2004.

5. Ministério do Trabalho e Emprego. Secretaria de Políticas Públicas de Emprego. Plano

Nacional de Qualificação 2003-2007. Brasília: 2003. Disponível em: <http://portal.mte.gov.br/data/files/FF8080812CD2239D012CE1DFCF3A6064/proesq.pdf>. Acesso em: 01 Mar. 2015.

6. _ 0 Fórum Brasileiro de Economia Solidária (FBES). Disponível em: <http://www.fbes.org.br/index.php?option=com_content\&task=view\&id=61\&ltemid=57/>. Acesso em: 04 Mar. 2014.

7. Sistema Nacional de Informações em Economia Solidária (SIES). Atlas da Economia Solidária no Brasil, do Ministério do Trabalho e Emprego. 2015. Disponível em: $<$ http://portal.mte.gov.br/ecosolidaria/sistema-nacional-de-informacoes-em-economiasolidaria/>. Acesso em: 01 Mar. 2015.

8.

Sistema Nacional de Informações em Economia Solidária (SIES). Economia Solidária: uma outra economia acontece. Cartilha da Campanha Nacional de Mobilização Social. Brasília: SENAES/MTE, 2007. Disponível em: < http://portal.mte.gov.br/data/files/FF8080812B59B49C 012B5DD948C22F07/impresso3_cartilha_32pg_web.pdf>. Acesso em: 01 Mar. 2014.

$9 . \quad$ Sistema Nacional de Informações em Economia Solidária (SIES). Oficina Nacional de Formação/Educação em Economia Solidária. Relatório Final. Brasília: SENAES/MTE, 2005.

10. Sistema Nacional de Informações em Economia Solidária (SIES). Resolução no 04 , de 04 de JULHO de 2012. Plano Brasil Justo e Solidário: agenda trans versal PPA 2012-2015. Brasília: 2012. Disponível em: < http://portal.mte.gov.br/data/files/8A7C812D3CB58904013CB5B930233D49/RESOLUCAO\%20 4\%20WEB.pdf>. Acesso em: 01 Mar. 2014.

11. Secretaria Nacional de Economia Solidária. Termo de Referência do Sistema de Informações em Economia Solidária - SIES. Brasília: SENAES/MTE, 2004. (mimeo).

12. Senado. Resolução n.o 333/2003. Conselho Deliberativo do Fundo de Amparo ao Trabalhador, Brasília (DF): 10 de julho de 2003. Disponível em: <http://www.diariodasleis .com.br/busca/exibelink.php?numlink=1-37-34-2003-07-10-333> Acesso em: 01 Mar. 2014.

13. BRASÍLIA. Câmara dos Deputados. Projeto de Lei PL 4685/2012. Dispõe sobre a Política Nacional 
de Economia Solidária e os Empreendimentos Econômicos Solidários, cria o Sistema Nacional de Economia Solidária e dá outras providências. Disponível em: <http://www.camara. gov.br/proposicoesWeb/fichadetramitacao?idProposicao=559138> . Acesso em: 01 Mar. 2015.

14. CASTORIADIS, C. As encruzilhadas do labirinto III: o mundo fragmentado. Tradução de Rosa Maria Boaventura. São Paulo: Paz e Terra, 1992.

15. DEL, Roio, Marcos. Gramsci e a emancipação do subalterno. Rev. Sociol. Polít., Curitiba, 29, p. 63-78, nov. 2007.

16. FREIRE, Paulo. Pedagogia do Oprimido. 14. ed. Rio de Janeiro: Paz e terra, 1985.

17. __ Educação e Mudança. 14. ed. Rio de Janeiro: Paz e terra, 1979.

18. __ Educação como prática da liberdade. Rio de Janeiro: Paz e terra, 1967.

19. GERRATANA, Valentino (ORg.). QuadernidelCarcere, v. 11, edição crítica do Instituto Gramsci. Turim: Einaudi, 1975.

20. GRAMSCI, A. Os Intelectuais e a Organização da Cultura. 4. ed. Rio de Janeiro: Civilização Brasileira, 1982.

21. MONASTA, Attilio. Antonio Gramsci. Recife: Massangana, 2010.

22. OLIVEIRA, Rosângela Alves de. Universidade e Economia Solidária: um diálogo necessário. Natal: EDURFRN, 2012.

23. PIOVESAN, Flávia; BARBIERI, Carla Bertolucci. Terceiro Setor e Direitos Humanos. In: CARVALHO, Cristiano; PEIXOTO, Marcelo Magalhães. Aspectos Jurídicos do Terceiro Setor. São Paulo: IOB Thompson, 2005, p. 75-97.

24. SINGER, Paul. É Possível Levar o Desenvolvimento a Comunidades Pobres? Brasília: SENAES/MTE, 2004. Disponível em: <http://acesso.mte.gov.br/data/files/FF8080812BCB27900 12BCF8C1B8E5087/prog_desenvolvimentocomunidadespobre.pdf/>. Acessoem: 20 Jun. 2015.

25. A Economia Solidária no Brasil: um retrato em 2005. Brasília: MTE/SENAES, 2007.

\title{
NOTAS
}

\begin{abstract}
'A economia solidária deve ser entendida como um modo de produção e distribuição que é reatualizado temporalmente, a partir da necessidade de inserção dos trabalhadores na economia e na busca de postos de trabalho, em contraposição ao modo de produção capitalista (SINGER, 2000).

ii São organizações coletivas, autogestionárias, permanentes, e que realizam atividades econômicas de produção de bens, de prestação de serviços, de fundos de crédito de comercialização e/ou de consumo solidário (SENAES).

iiisistema Nacional de Informações em Economia Solidária é o resultado deste mapeamento, e consiste em banco de dados dos empreendimentos de economia solidária de todo o Brasil. Ele é composto por informações de Empreendimentos Econômicos Solidários (EES) e de Entidades de Apoio, Assessoria e Fomento (EAF).

iv A secretaria foi criada no âmbito do Ministério do Trabalho e Emprego e fomenta por todo o país a geração de trabalho e renda através de uma forma diferenciada de organização do trabalho, a Economia Solidária, ${ }^{[2]}$ na tentativa de evitar grandes desigualdades de políticas neoliberais.

vProjeto de Lei que dispõe sobre a Política Nacional de Economia Solidária e os Empreendimentos Econômicos Solidários, como também a criação do Sistema Nacional de Economia Solidária e dá outras providências.

vi Está organizado em todo o país em mais de 160 Fóruns Municipais, Microrregionais e Estaduais, envolvendo diretamente mais de 3.000 empreendimentos de economia solidária, 500 entidades de assessoria, 12 governos estaduais e 200 municípios pela Rede de Gestores em Economia Solidária.
\end{abstract}

